Original Research Paper

\title{
Determination of Draft Force for a 3-bottom Disc Plough Under Sandy Loam Soil Conditions
}

\author{
${ }^{1}$ Paul Okoko and ${ }^{2}$ Emmanuel A. Ajav \\ ${ }^{1}$ Department of Agricultural and Food Engineering, Faculty of Engineering, University of Uyo, Uyo, Nigeria \\ ${ }^{2}$ Department of Agricultural and Environmental Engineering, Faculty of Technology, University of Ibadan, Ibadan, Nigeria
}

\author{
Article history \\ Received: 15-02-2020 \\ Revised: 06-04-2020 \\ Accepted: 12-05-2020 \\ Corresponding Author: \\ Paul Okoko \\ Department of Agricultural and \\ Food Engineering, Faculty of \\ Engineering, University of \\ Uyo, Uyo, Nigeria \\ Email: okokokizito@gmail.com
}

\begin{abstract}
This study was performed to determine the draft force for a 3bottom disc plough under sandy loam soil conditions. The experiments were conducted using five different tractor speeds $(3.6,5.4,7.2,9.0$ and 10.8 kilometer per hour $(\mathrm{km}))$ and three tillage depths $(10,20$ and 30 centimeter $(\mathrm{cm})$ ) with a view to determine the actual implement speed at the different tillage depths. The implement speed determined from the experiment was used to determine the draft force. The effects of tillage depths and implement speeds on draft force for the 3-bottom disc plough were investigated. The results showed that increasing the tillage depth and implement speed increased draft force and the effects appeared to be linear. At a tillage depth of $10 \mathrm{~cm}$, draft force for this implement at implement speed of 0.82 and 2.58 meter per second $(\mathrm{m} / \mathrm{s})$ were 0.92 and 1.18 kilonewton $(\mathrm{kN})$, respectively while at $30 \mathrm{~cm}$, the draft force at 0.82 and $2.58 \mathrm{~m} / \mathrm{s}$ were 3.83 and $4.67 \mathrm{kN}$, respectively. A regression equation to predict draft force for 3-bottom disc plough in a sandy loam soil was developed based on tillage depth and implement speed parameter. A significant increase in draft force at 0.05 level of significance was seen for the implement with an increase in tillage depth and implement speed. This study recommends that the root length of the crop for which tillage is made should be considered in the selection of the tillage depth.
\end{abstract}

Keywords: Implement Speed, 3-Bottom Disc Plough, Tillage Depth, Tractor, Soil

\section{Introduction}

Tillage is a process which mechanically modifies or manipulates the soil by cutting, pulverising and inverting in order to provide conditions favourable to crop growth (Anazodo, 1982). It is a physical, chemical or biological process which manipulates the soil to optimise conditions for seed germination and seeding emergence and establishment. Tillage is an integral part of crop production system and usually account for a high proportion of total energy spent in crop production (Anazodo et al., 1986).

Oni et al. (1992) that soil strength is the ability or capacity of a soil in a particular condition to resist or endure on applied force. Penetration resistance is a composite parameter that involves several independent properties of a soil but is generally considered to reflect the strength of the soil. To measure penetration resistance, a simple instrumented probe known as a penetrometer is pushed into the soil and the force in observed in relation to penetration depth. Penetrometer force readings per unit of base cross-sectional area provide indications of relative strengths of different soils and of uniformity versus depth in a particular soil condition.

Implement forces and change in soil condition are the two basic aspects of tillage-implement performance. The implement should accomplish the necessary soil manipulation with a minimum of energy input and the final soil condition must be acceptable when compared with the desired conditions. The force systems acting on tillage implements can be represented mathematically and the forces can be measured (Harrigan and Rotz, 1994).

Evaluation of performance involves comparing the actual final soil condition with the desired condition. The desired condition is determined entirely by the intended use of the tilled soil. The acceptable level of functional performance, assuming it is below the desired level, may be tampered by economic considerations and other factors. Performance also includes field capacity and energy utilization efficiency which must be considered when comparing two or more implements (Fielke, 1996). 
To evaluate a tillage operation in terms of energy utilization, the actual tillage energy input per unit volume is calculated from the measured draft force, width of cut and depth of cut.

Salokhe et al. (1989) provide that draft is the component of pull in the direction of travel. The simplest device for measuring pull is a spring-type dynamometer that is connected between the tractor drawbar and the implement hitch and is read directly. Because of rapid fluctuations in load, such a dynamometer is suitable only for rough measurements. A hydraulic type transmitting pressure to a bourdon gage calibrated in force units, is easier to read than the spring type because force fluctuations can be damped considerably by using a viscous fluid or having a restriction in the line to the gage.

To provide a complete picture of implement draft force, it is necessary to measure speed and the width and depth of cut in addition to determining the draft force. Because of wide fluctuations in soil conditions and draft force, even within a short run, it is desirable to record at least the pull in relation to travel distance. Integration of the area under the curve then gives the total work and average pull. Speed may be determined by timing a measured or automatically recorded travel distance or with a tachometer generator driven from a ground wheel (Stafford, 1979).

Kepner et al. (1982) that the energy required for soil breakup is related to the desired degree of pulverization. The amount of energy required to produce a given degree of pulverization depends primarily upon the soil strength and the energy utilization efficiency of the implement. Soil strength is related to the nature of the soil and to its physical condition. Clay soils have higher breakup-energy requirements than sandy soils or loams.

The strength of an initially moist soil increases considerably as the soil dries out, particularly with clays and clay loams, thereby increasing the pulverization energy requirements as reported by Kushwaha and Linke (1996).

Depth of cut, width of cut and implement shape, implement arrangement and travel speed are factors that may affect draft force and the energy utilization efficiency for a specific soil condition. The effects of these parameters vary with different types of implements and with different soil conditions (Subrata et al., 2015)

Kepner et al. (1982) stated that with chisel-type implements, average specific draft force in a primary tillage operation generally shows a slight or moderate increase with depth. Improper location of wheels, runners, or adjustment of implements can interfere with the normal soil failure pattern and this can lead to increase draft force. Shape and orientation of implements are significant factors in regard to draft force as reviewed by Ojhai and Michael (2006).
The main objective of this study is to determine draft force for a 3-bottom disc plough under sandy loam soil conditions. The specific objectives are to study the effects of tillage depth and implement speed on draft force, carryout analysis of variance of tillage depth and implement speed on draft force and develop regression equation based on these parameters.

\section{Materials and Methods}

\section{Study Location}

The study was conducted at Mbiabong in Uyo Local Government Area of Akwa Ibom State, Nigeria. Akwa Ibom State is in the South-South geopolitical zone of Nigeria with coordinates: $5^{\circ} 01^{\prime} 24^{\prime \prime} \mathrm{N}, 7^{\circ} 55^{\prime} \quad 26^{\prime}$ $\mathrm{E} / 5.0232309^{\circ} \mathrm{N} 7.9238892^{\circ} \mathrm{E}$. Uyo local government area has a land mass of $115 \mathrm{~km}^{2}$ (44 sq mi) and metropolis area mass of $168 \mathrm{~km}^{2}$ (65 sq mi).

\section{Tractor and Tillage Implement}

The specifications of the tractor and the tillage implement used for the field experiment are presented in Table 1 and 2 .

\section{Experimental Setup}

The experiment was performed at Mbiabong, Uyo Local Government Area of Akwa Ibom State, Nigeria. Soil samples were collected during the tillage experiment to determine the soil conditions in which the experiment was performed. The samples were weighed using a weighing balance and the weight of each sample was recorded. Then the samples were placed in an oven maintained at 110 degree celsius for $24 \mathrm{~h}$. The dried soil samples were re-weighed and the weight was again recorded. The moisture contents were calculated on a dry weight basis.

Table1: Specifications of tested tractor

\begin{tabular}{ll}
\hline Specification & Value \\
\hline Manufacturer & Swaraj tractor, model 978 \\
Effective output (horsepower) & 72 (53.7 kilowatt) \\
Type of Engine & 4-cylinder \\
Type of Fuel & Diesel \\
Type of steering system & Power assisted \\
Type of injector pump & In-line injector \\
Fuel tank capacity (L) & 98 \\
Lifting capacity (kg) & 1250 \\
Rated engine speed (rpm) & 2200 \\
Type of cooling system & Water-cooled \\
Country of manufacture & China \\
Front tyres (size) & $6.0-16$ \\
Inflation pressure (kPa) & 360 \\
Rear tyres (size) & $14.9-28$ \\
Inflation pressure (kPa) & 180 \\
\hline
\end{tabular}

Source: Tractor manual 
Table 2: Specifications of a 3-bottom disc plough

\begin{tabular}{lll}
\hline S/No & Parameter & Volume \\
\hline 1. & Type (Hitching) & Fully mounted \\
2 & Width of implement (centimeter) & 116 \\
3. & Number of bottoms & 3 \\
4. & Diameter of bottom (centimeter) & 65.3 \\
5. & Spacing of bottoms (centimeter) & 68 \\
6. & Actual width of cut (centimeter) & 95.1 \\
7. & Disc angle (degree) & 45 \\
8. & Rake angle (degree) & 49 \\
9. & Tilt angle (degree) & 20 \\
10. & Type of disc blade & Plain concave \\
11. & Weight of implement (kilogram) & 360 \\
\hline
\end{tabular}

Source: By measurement

\section{Experimental Design and Procedure}

The experiment was conducted in Mbiabong, Uyo Local Government Area of Akwa Ibom State, (sandy loam soil) with 3-bottom disc plough. The parameters investigated for the determination of draft force for a 3bottom disc plough were three levels of tillage depth (10, 20 and $30 \mathrm{~cm}$ ) and five levels of tractor speed (3.6, 5.4, $7.2,9.0$ and $10.8 \mathrm{~km} / \mathrm{h}$ ). During the field experiment, the tractor was operated at the same speeds for the different tillage depths. An experimental plot of $100 \mathrm{~m}$ long by 50 $\mathrm{m}$ wide was used for the experiment. A plot of $30 \mathrm{~m}$ long by $10 \mathrm{~m}$ wide was used as a practice area prior to the beginning of the experimental runs to enable the tractor and the reach the required depth. There were fifteen (15) runs i.e., in the factorial of $1 \times 3 \times 5$ (one implement, three tillage depths and five tractor speeds) replicated three times resulting in a total of forty five (45) runs. The different tractor speeds (3.6$10.8 \mathrm{~km} / \mathrm{h}$ ) were achieved by selecting appropriate gears and adjusting engine throttle at engine speeds of between 1600 and $2000 \mathrm{rpm}$ while the tillage depths $(10-30 \mathrm{~cm})$ were achieved by using tractor depth controller through its quadrant. Tillage depth was measured as a vertical distance from the top of the undisturbed soil surface to the implement's deepest penetration using a steel measuring tape.

The time taken for the implement to travel a distance of $100 \mathrm{~m}$ was taken and recorded. The distance was divided by the time taken to obtain the implement travel speed.

Statistical Package for Social Sciences (SPSS) software program was used for analysis on a personal computer. The Duncan Multiple Range Test (DMRT) and Tukey HSD were used for the comparison test.

Determination of Angle of Internal Friction (SoilSoil) and Soil Cohesion

Soil cohesion and soil angles of internal friction (soilsoil) were determined using the direct shear test method as described by Mamman and Oni (2005). The coefficient of friction (soil on soil) was determined using an equation given by Ejit et al. (2006):

$$
\mu=\tan \Phi=\frac{F}{N}
$$

Where:

$\mu=$ Coefficient of friction (soil on soil)

$F=$ Frictional force tangent to the surface, $N$

$N=$ Normal force (perpendicular to the surface), $N$

$\Phi=$ Angle of internal friction, deg

\section{Determination of Shear Strength of Soil}

The strength of the soil in the studied locations was determined using an equation given by Ejit et al. (2006) as:

$S=c+\delta \tan \Phi$

Where:

$S=$ Shear strength of the soil, $k P a$

$C=$ Soil cohesion, $k P a$

$\delta=$ Normal stress, $k P a$

$\Phi=$ Angle of internal soil friction, $\mathrm{deg}$

\section{Determination of Weight of Soil}

The weight of soil was determined from the equation according to Ejit et al. (2006):

$W=\rho b d *\left(L_{0}+\frac{L_{1}+L_{2}}{2}\right)$

Where:

$W=$ Weight of soil, $N$

$\rho=$ Bulk density of soil, $\mathrm{kg} / \mathrm{m}^{3}$

$b=$ Width of implement, $m$

$d=$ Tillage depth, $m$ :

$d^{*}=d((\sin (\delta+\beta)) / \sin \beta, m$

$L_{0}=$ Length of implement, $m$ :

$L_{1}=d((\cos (\delta+\beta)) / \sin \beta, m$

$L_{1}=$ Length of implement in relation to tillage depth:

$L_{2}=d^{*} \tan \delta, m$

$L_{2}=$ Length of implement in relation to rake angle

$\delta=$ Rake angle, deg:

$\beta=\frac{90^{\circ}-\Phi}{2}, \mathrm{deg}$ 
$\Phi=$ Angle of internal friction, degree

\section{Determination of Draft Force}

The draft force of the implement was determined using the equation as given by Ejit et al. (2006):

$D=\frac{W}{Z}+\frac{c\left(\frac{b d}{\sin \beta}\right)+\rho b d v_{o}^{2} \sin \delta / \sin (\delta+\beta)}{Z(\sin \beta+\mu \cos \beta)}$

Where:

$D=$ Draft force of tillage implement, $N$

$W=$ Weight of soil, $N$

$c=$ Soil cohesion, $k P a$

$\mu=$ Coefficient of internal soil friction

$\beta=$ Angle of the forward failure surface, $\mathrm{deg}$

$V_{o}=$ Implement travel speed, $\mathrm{m} / \mathrm{s}$ :

$Z=\frac{\cos \delta-\mu^{\prime} \sin \delta}{\sin \delta+\mu^{\prime} \cos \delta}+\frac{\cos \beta-\mu \sin \beta}{\sin \beta+\mu \cos \beta}$

$\mu^{\prime}=$ Coefficient of internal soil-metal friction

\section{Results and Discussion}

\section{Soil Analysis Test for the Location}

Analysis of soil test was carried out at the study location for the tillage implement. The results of the analysis test of the soil are presented in Table 3.

\section{Influence of Speed and Tillage Depth on Draft Force for a 3-Bottom Disc Plough}

Figure 1 shows the effect of tractor forward speed on draft force at different levels of tillage depth and the effect of tillage depth on draft force at different levels of tractor forward speed for 3-bottom disc plough operating on a sandy loam soil. From this figure, it was noticed that draft force increased with increase in tractor forward speed and tillage depth. At a tillage depth of 10 centimeter $(\mathrm{cm})$, draft force increased from 920.6 to 1177.4 Newton $(\mathrm{N})$ at implement speeds of 0.82 and 2.58 meter per second $(\mathrm{m} / \mathrm{s})$, respectively. The draft force obtained at an implement speed of $0.82 \mathrm{~m} / \mathrm{s}$ increased from 920.6 to $3828.9 \mathrm{~N}$ at tillage depths of 10 and $30 \mathrm{~cm}$, respectively while at speed of $2.58 \mathrm{~m} / \mathrm{s}$, draft force increased from 1177.4 to $4666.3 \mathrm{~N}$ at tillage depths of 10 and $30 \mathrm{~cm}$, respectively. For a tillage depth of $30 \mathrm{~cm}$, draft force increased from 3828.9 to 4666.3 $\mathrm{N}$ at implement speeds of 0.82 and $2.58 \mathrm{~m} / \mathrm{s}$, respectively.

Table 3: Mechanical properties of the soil at location

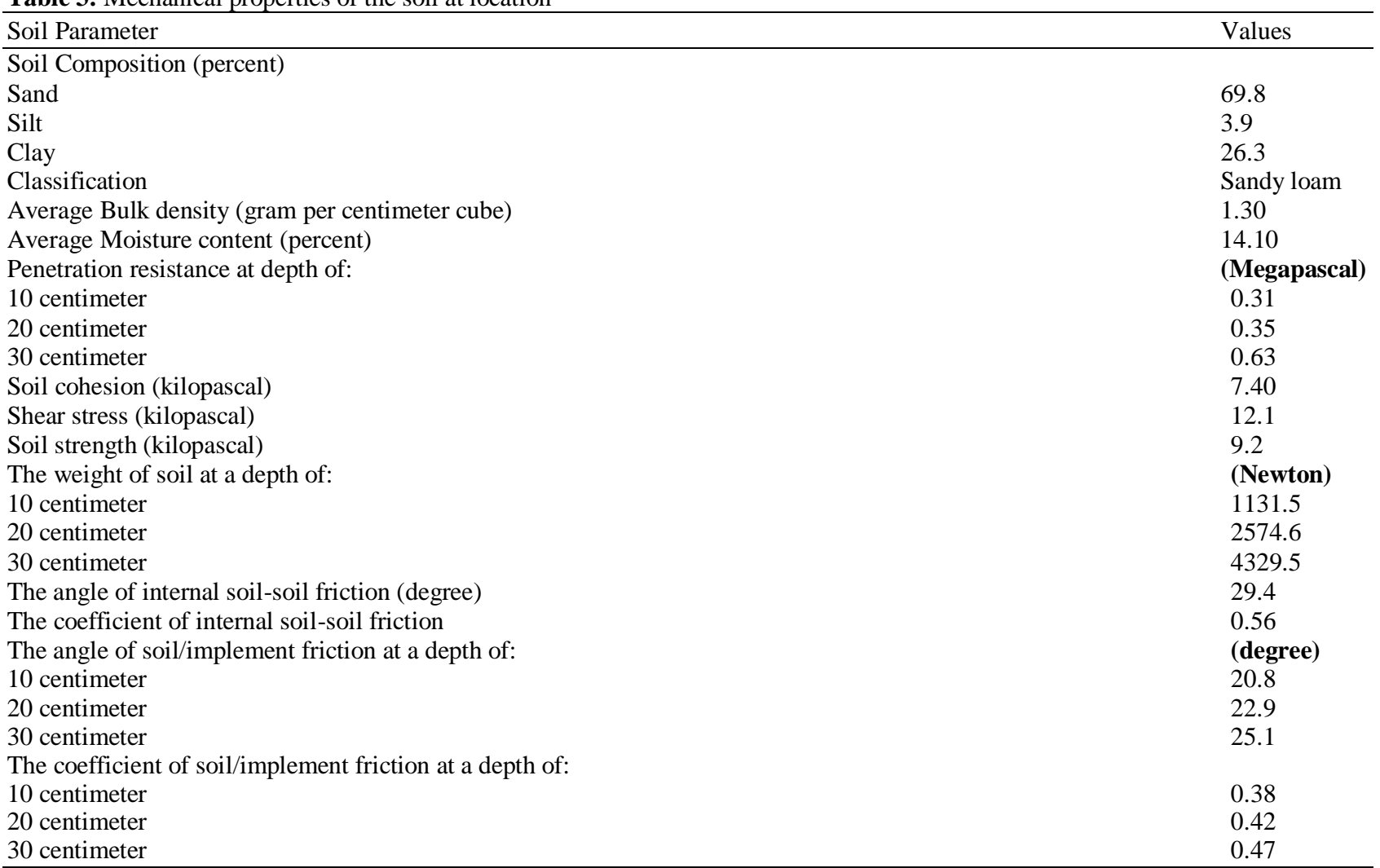


From Tables 4 and 5, it was observed that the increase in draft force for 3-bottom disc plough in these soils with the tillage depth and/or the forward speed appeared to be linear. For all tillage depths, the observed increase in draft force when the forward speed was increased from 0.82 to $1.37 \mathrm{~m} / \mathrm{s}$ was lower than the observed increase in draft force when the forward speed was increased from 1.37 to 1.93 $\mathrm{m} / \mathrm{s}$ and the observed increased in draft force was higher when the speed was increased from 1.93 to $2.32 \mathrm{~m} / \mathrm{s}$ than the observed increased in draft force when the speed was increased from 1.37 to $1.93 \mathrm{~m} / \mathrm{s}$ while the observed increase in draft force was highest when the speed was increased from 2.32 to $2.58 \mathrm{~m} / \mathrm{s}$. It was also observed that the increased in draft force when the depth was increased from 20 to $30 \mathrm{~cm}$ was higher than the increase in draft force when the depth was increased from 10 to $20 \mathrm{~cm}$ for all forward speed. It appeared also that the tillage depth had more effect on the draft force than the forward speed.

Tables 6 and 7 show the analysis of what happens at different implement speeds and tillage depths for 3-bottom disc plough on sandy loam soil. From these tables, it was seen that the percentage increase in average draft force when the implement speed was increased from 1.37 to 1.93 $\mathrm{m} / \mathrm{s}$ was higher than the percentage increase in the average draft force when the implement speed was increased from 0.82 to $1.37 \mathrm{~m} / \mathrm{s}$ and from 1.93 to $2.32 \mathrm{~m} / \mathrm{s}$ for this soil type. This may indicate that the implement speed of $1.93 \mathrm{~m} / \mathrm{s}$ using 3-bottom disc plough in this soil is the optimum speed. It was also observed that the percentage increase in average draft force when the depth was increased from 10 to $20 \mathrm{~cm}$ was higher than the percentage increase in average draft force when the depth was increased from 20 to $30 \mathrm{~cm}$ for the soil type. This may suggest that the tillage depth of $20 \mathrm{~cm}$ is the optimum. However, the depth of the crop roots will be a deterministic factor of tillage depth.

\section{Analysis of Variance for Speed and Depth on Draft} for 3 - Bottom Disc Plough

The results of the Analysis Of Variance (ANOVA) for the test of speed and depth effect on draft force for 3bottom disc plough at Mbiabong (sandy loam soil) is presented Table 8 . The result shows that there is significant mean difference between the interaction of speed and depth on draft force. Hence, we can see from the tables that there was significant effect of speed and depth on draft force $P=<0.0001(P<0.05)$. A two-way ANOVA was conducted to examine the effect of speed and depth on draft force. There was a significant interaction between the effects of speed and depth on draft force for 3-bottom disc plough $P=<0.0001$.

Table 9 shows the effect of speed on mean draft force for 3-bottom disc plough at Mbiabong (sandy loam soil). Tukey test show 3 subset while Duncan test gives 4 subset for the different levels of speed. Duncan test shows that there is no significant difference between 0.82 and $1.37 ; 1.37$ and $1.93 ; 1.93$ and $2.32 ; 2.32$ and $2.58 \mathrm{~m} / \mathrm{s}$. While Tukey test shows that there is no significant difference between $0.82,1.37$ and $1.93 ; 1.37$, 1.93 and $2.32 ; 1.93,2.32$ and $2.58 \mathrm{~m} / \mathrm{s}$.

Table 10 indicates the effect of depth on mean draft force for 3-bottom disc plough at Mbiabong (sandy loam soil). The table shows that there is significant difference between depth of 10,20 and $30 \mathrm{~cm}$ on the mean draft force for both Duncan and Tukey tests.

\section{Regression Equation Developed}

The result of the regression equation obtained from the analysis for 3-bottom disc plough on a sandy loam soil is presented below:

$$
\begin{aligned}
& D F=347.48-329.64 \mathrm{~s}+1649 \mathrm{sd}+90.48 \mathrm{~s}^{2} \\
& +4558 \mathrm{~d}+21150 \mathrm{~d}^{2} R^{2}=0.99990
\end{aligned}
$$

Where:

$\mathrm{DF}=$ Draft force, $N$

$\mathrm{d}=$ Tillage depth, $\mathrm{cm}$

$\mathrm{s} \quad=$ Implement speed, $\mathrm{m} / \mathrm{s}$

From this equation, it was observed that the coefficient of determination value obtained from the equation was very high and this would make the equation suitable for predictive purpose

Table 4: The incremental increase in draft force with increases in forward speed at various depths for 3-bottom disc plough at Mbiabong (sandy loam soil)

\begin{tabular}{lll}
\hline Depth $(\mathrm{cm})$ & $\begin{array}{l}\text { Forward speed } \\
\text { interval }(\mathrm{m} / \mathrm{s})\end{array}$ & $\begin{array}{l}\text { Increase in draft } \\
\text { force }\left(\mathrm{N} / \mathrm{msec}^{1}\right)\end{array}$ \\
\hline 10 & $0.82-1.37$ & 94.00 \\
& $1.37-1.93$ & 141.61 \\
& $1.93-2.32$ & 182.31 \\
& $2.32-2.58$ & 210.38 \\
20 & $0.82-1.37$ & 194.18 \\
& $1.37-1.93$ & 292.68 \\
& $1.93-2.32$ & 376.67 \\
30 & $2.32-2.58$ & 434.61 \\
& $0.82-1.37$ & 306.54 \\
& $1.37-1.93$ & 461.78 \\
& $1.93-2.32$ & 594.61 \\
& $2.32-2.58$ & 685.77 \\
\hline
\end{tabular}

Table 5: The incremental increase in draft force with increases in depth at various speeds for 3-bottom disc Plough at Mbiabong (sandy loam soil)

\begin{tabular}{lll}
\hline Speed $(\mathrm{m} / \mathrm{s})$ & $\begin{array}{l}\text { Increase in draft } \\
\text { force }(\mathrm{cm})\end{array}$ & $\begin{array}{l}\text { Depth intervals } \\
(\mathrm{N} / \mathrm{m})\end{array}$ \\
\hline 0.82 & $10-20$ & 12609.00 \\
& $20-30$ & 16574.00 \\
& $10-20$ & 13060.00 \\
1.37 & $20-30$ & 17192.00 \\
& $10-20$ & 13906.00 \\
1.93 & $20-30$ & 18139.00 \\
& $10-20$ & 14664.00 \\
2.32 & $20-30$ & 18989.00 \\
& $10-20$ & 15247.00 \\
2.58 & $20-30$ & 19642.00 \\
\hline
\end{tabular}


Paul Okoko and Emmanuel A. Ajav / American Journal of Agricultural and Biological Sciences 2020, Volume 15: 60.67 DOI: 10.3844/ajabssp.2020.60.67

Table 6: Range of speed and the corresponding percentage increase of draft force for 3-bottom disc Plough at Mbiabong (sandy loam soil)

\begin{tabular}{lllll}
\hline Speed $(\mathrm{m} / \mathrm{s})$ & Average draft force $(\mathrm{N})$ & Range of speed $(\mathrm{m} / \mathrm{s})$ & Average draft force increase $(\mathrm{N})$ & Percentage increase $(\%)$ \\
\hline 0.82 & 2307.00 & $0.82-1.37$ & 109.03 & 4.7 \\
1.37 & 2416.03 & $1.37-1.93$ & 167.27 & 6.9 \\
1.93 & 2583.30 & $1.93-2.32$ & 149.96 & 5.8 \\
2.32 & 2733.26 & $2.32-2.58$ & 115.34 & 4.2 \\
2.58 & 2848.60 & & & \\
\hline
\end{tabular}

Table 7: Range of depth and the corresponding percentage increase of draft force for 3-buttom disc Plough at Mbiabong (sandy loam soil)

\begin{tabular}{|c|c|c|c|c|}
\hline Depth $(\mathrm{cm})$ & Average draft force $(\mathrm{N})$ & Range of depth $(\mathrm{cm})$ & Average draft force increase $(\mathrm{N})$ & percentage increase $(\%)$ \\
\hline 10 & 1048.92 & $10-20$ & 1387.72 & 132.3 \\
\hline 20 & 2436.64 & $20-30$ & 1810.72 & 74.3 \\
\hline 30 & 4879.34 & & & \\
\hline
\end{tabular}

Table 8: Analysis of Variance (ANOVA) for speed and depth on draft force for 3-bottom disc plough at Mbiabong (Sandy soil)

\begin{tabular}{lccccc}
\hline Source & Type III Sum of Squares & df & Means Square & F & Sig. \\
\hline Corrected Mode & 26315254.8 & 6 & 4385875.801 & 309.569 & $<0.0001^{*}$ \\
Intercept & 99663419.54 & 1 & 99663419.54 & 7034.560 & $<0.0001^{*}$ \\
Speed & 591101.223 & 4 & 147775.306 & 10.430 & $0.003^{*}$ \\
Depth & 25724153.58 & 2 & 12862076.79 & 907.846 & $<0.0001^{*}$ \\
Error & 113341.469 & 8 & 14167.684 & & \\
Total & 126092015.8 & 15 & & & \\
Corrected Total & 26428596.28 & 14 & & & \\
\hline
\end{tabular}

* Significant at 0.05 level

Table 9: Effect and comparison of speed on mean draft force for 3-bottom disc plough at Mbiambong (sandy loam soil)

\begin{tabular}{|c|c|c|c|c|c|c|c|}
\hline & Speed $(\mathrm{m} / \mathrm{s})$ & $\mathrm{N}$ & 1 & subset & 2 & 3 & 4 \\
\hline \multirow[t]{6}{*}{ Tukey HSD ${ }^{\mathrm{a}, \mathrm{b}}$} & 0.82 & 3 & 2307.0 & & & & \\
\hline & 1.37 & 3 & 2416.0 & 2416.0 & & & \\
\hline & 1.93 & 3 & 2583.3 & 2583.3 & 2583.3 & & \\
\hline & 2.32 & 3 & & 2733.2 & 2733.2 & & \\
\hline & 2.58 & 3 & & & 2848.6 & & \\
\hline & Sig. & & 0.115 & 0.065 & 0.134 & & \\
\hline \multirow[t]{6}{*}{ Duncan $^{\mathrm{a}, \mathrm{b}}$} & 0.82 & 3 & 2307.0 & & & & \\
\hline & 1.37 & 3 & 2416.0 & 2416.0 & & & \\
\hline & 1.93 & 3 & & 2583.3 & 2583.3 & & \\
\hline & 2.32 & 3 & & & 2733.2 & 2733.2 & \\
\hline & 2.58 & 3 & & & & & 2848.6 \\
\hline & Sig. & & & 0.294 & 0.124 & 0.161 & 0.269 \\
\hline
\end{tabular}

Means for groups in homogeneous subsets are displayed.

Based on observed means.

The error term is Mean Square (Error) $=14167.684$.

a. Uses harmonic mean sample size $=3.000$.

b. Alpha $=0.05$

Table 10: Effect and comparison of depth on mean draft force for 3-bottom disc plough at Mbiabong (sandy loam soil)

\begin{tabular}{|c|c|c|c|c|c|}
\hline & \multirow[b]{2}{*}{ Tillage Depth $(\mathrm{cm})$} & \multirow[b]{2}{*}{$\mathrm{N}$} & \multicolumn{3}{|l|}{ Subset } \\
\hline & & & 1 & 2 & 3 \\
\hline \multirow[t]{4}{*}{ Tukey HSD ${ }^{\mathrm{a}, \mathrm{b}}$} & 10 & 5 & 1048.920 & & \\
\hline & 20 & 5 & & 2436.640 & \\
\hline & 30 & 5 & & & 4247.360 \\
\hline & Sig. & & 1.000 & 1.000 & 1.000 \\
\hline \multirow[t]{4}{*}{ Duncan $^{\mathrm{a}, \mathrm{b}}$} & 10 & 5 & 1048.920 & & \\
\hline & 20 & 5 & & 2436.640 & \\
\hline & 30 & 5 & & & 4247.360 \\
\hline & Sig. & & 1.000 & 1.000 & 1.000 \\
\hline
\end{tabular}

Means for groups in homogeneous subsets are displayed.

Based on observed means.

The error term is Mean Square (Error) $=14167.684$.

a. Uses harmonic mean sample size $=5.000$.

b. Alpha $=0.05$. 


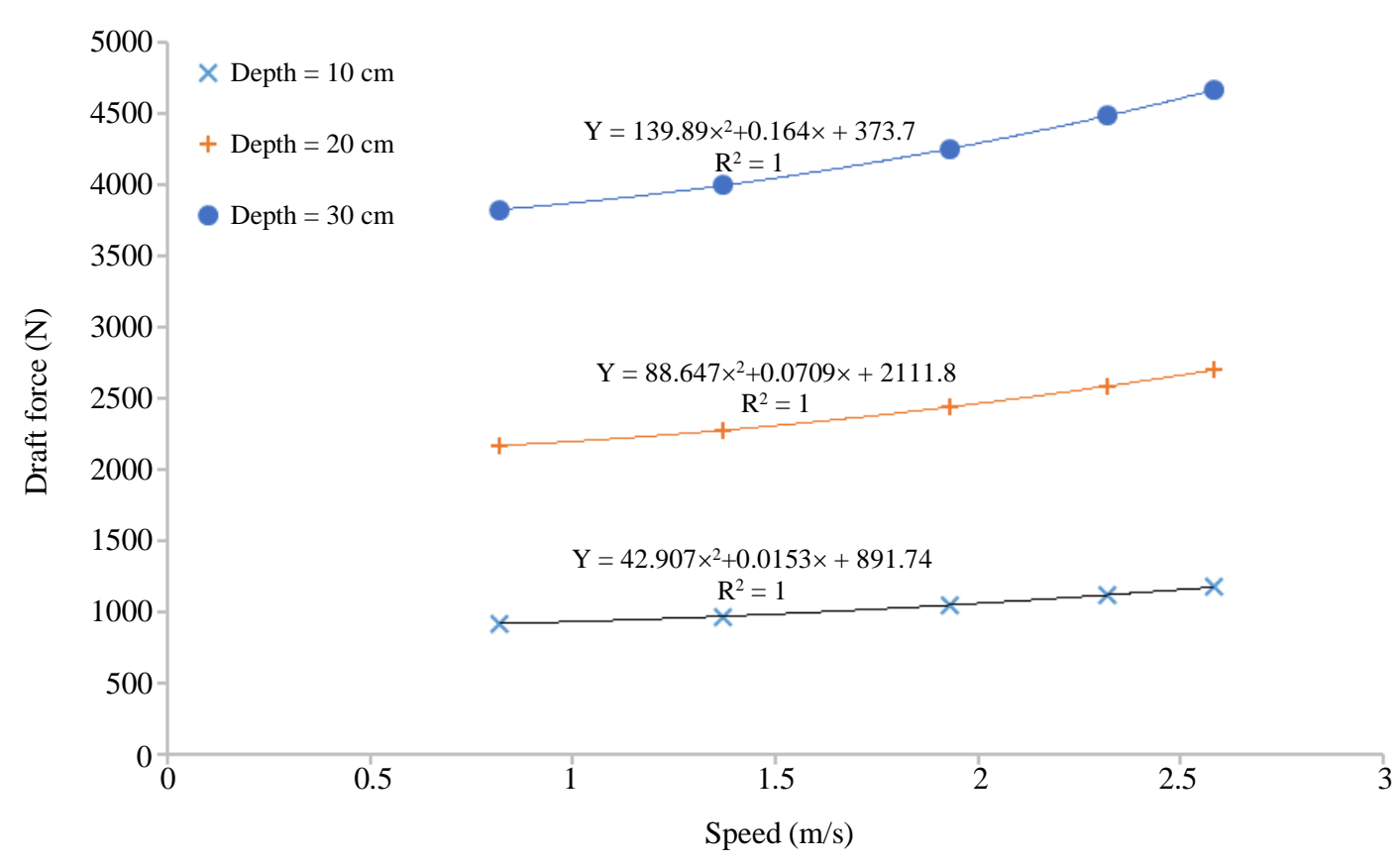

Fig. 1: Effects of tillage depth and speed on draft force for a 3-bottom disc plough

\section{Conclusion}

The effects of tillage depths and implement speeds on draft force for a 3-bottom disc plough operating on a sandy loam soil were evaluated. The findings showed that increasing the tillage depth and implement speed increased draft force. Analysis Of Variance (ANOVA) indicated that both tillage depth and implement speed had significant effect $(p \leq 0.05)$ on draft force. Also, the interaction between tillage depth and implement speed was significant $(p \leq 0.05)$. There is disagreement between Duncan and Turkey tests on the effects of different levels of implement speed on draft force while both tests agreed on the effects of different levels of tillage depth on draft force. The coefficient of determination $\left(R^{2}\right)$ was seen to be high and this would make the regression equation suitable for predictive purposes. This study therefore recommends that the root length of the crop to be planted for which tillage is made should be considered in the selection of the tillage depth.

\section{Acknowledgement}

We are grateful to the University of Uyo for allowing us use the tractor and the implement at faculty of engineering, Department of Agricultural and Food Engineering. We equally extend our gratitude to Engr. K.C Umani for proof reading the manuscript before submission.

\section{Author's Contributions}

Paul Okoko: Involved in all the experiments, coordinated the data analysis and contributed immensely to the write up of the manuscript.
Emmanuel A. Ajav: Designed the experimental plan and organized the study.

\section{Ethics}

There are no ethical issues that will arise after the publication of this manuscript.

\section{References}

Anazodo, U.G., 1982. Mechanization of family farms in Nigeria. Agric. Mechaniz. Asia, Africa Latin Am., 8: 59-65.

Anazodo, U.G., H. Horrio and G. Sign, 1986. Agricultural machinery, uses in Nigeria, the Experience of decades. Proc. Nigerian Society Agric. Eng., 2: 406-429.

Ejit, K.S., E.G. Carroll, P.R. Roger and R.B. Dennis, 2006. Engineering Principles of Agricultural Machines. 2nd Edn., American Society of Agricultural Engineers, ISBN-10: 1892769506, pp: 588.

Fielke, J.M., 1996. Interactions of the cutting edge of tillage implements with soil. J. Agric. Eng. Res., 63: 61-72. DOI: 10.1006/jaer.1996.0008

Harrigan, T.M. and C.A. Rotz, 1994. Draught of major tillage seeding equipment. Am. Society Agric. Eng., 94: 1533-1533.

Kepner, R.A., R. Bainer and E.L. Barger, 1982. Principles of Farm Machinery. 3rd Edn., The Avi Publishing Company, ISBN-10: 087055252X, pp: 527.

Kushwaha, R.L. and C. Linke, 1996. Draught-speed relationship of simple tillage tools at high operating speeds. J. Soil Tillage Res., 39: 61-73.

DOI: 10.1016/S0167-1987(96)01052-5 
Mamman, E. and K.C. Oni, 2005. Draught performance of a range of model chisel furrowers. Agric. Eng. Int. CIGR J., 7: 1-16.

Ojhai, T.P. and A.M. Michael, 2006. Principles of Agricultural Engineering. 6th Edn., New York. McGraw-Hill, pp: 655.

Oni, K.C., S.J. Clark and W.H. Johnson, 1992. The effects of design on the draught of under cuttersweep tillage tools. J. Soil Tillage Res., 22: 117-130. DOI: 10.1016/0167-1987(92)90026-8
Salokhe, V.M., D. Gee-Clough and A.I. Mufti, 1989. Performance evaluation of an enamel coated moldboard plough. J. Agric. Eng., 3: 1633-1638.

Stafford, J.V., 1979. The performance of a rigid tine in relation to soil properties and speed. J. Agric. Eng. Res., 24: 41-56. DOI: 10.1016/0021-8634(79)90059-3

Subrata, K.M., M. Atanu, P. Ashok, K.M Palash and K. Sankar, 2015. Design and development of a suitable implement matching with low Hp tractor. Int. Res. J. Eng. Technol., 2: 539-542. 